\title{
Huanglongbing or yellow shoot, a disease of Gondwanan origin: Will it destroy citrus worldwide?
}

\author{
Joseph M. Bové
}

Received: 1 May 2014 / Accepted: 25 May 2014 /Published online: 6 July 2014

C) Springer Science+Business Media Dordrecht 2014

\section{Biography}

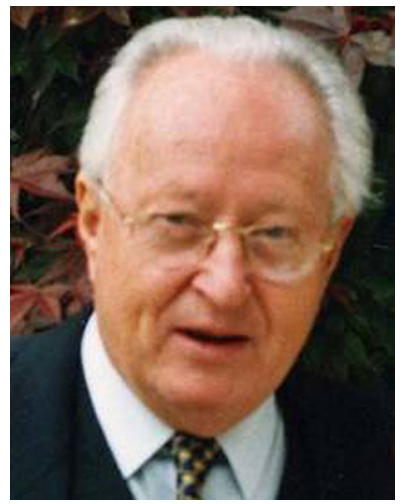

Joseph M. Bové was born in Luxemburg, 1929. French citizen since 1968. Higher education: School of Agronomy and University, Paris, France (1950-1955), University of California, Berkeley (1956-1955). Doctorate on in vitro synthesis of plant viral RNA (1967). Researcher at the French Institute for Citrus and Tropical fruit Research (1959-1970) at Versailles,

J. M. Bové $(\bowtie)$

University of Bordeaux \& INRA Research Center,

33883 Villenave d'Ornon, France

e-mail: joseph.bove@wanadoo.fr
France. Director of research at INRA (French National Institute for Agricultural Research), at INRA campus of Bordeaux, France (1971-1975) and professor of microbiology at University of Bordeaux (1976-1997). Head of Laboratory for Cellular and Molecular Plant Biology (1974-1994). President of INRA-Bordeaux (19841994). FAO consultant for citrus diseases (1981-1993). Consultant at Fundecitrus, São Paulo State, Brazil, for graft-transmissible diseases of citrus (1998-2014).

Research. (i) Photosynthetic phosphorylation, laboratory of Prof. D.I. Arnon, University of California at Berkeley (1956-1959). (ii) Replication of plant virus RNA, Versailles and Bordeaux (1959-1986). (iii) Discovery and study of pathogenic, phloem-restricted bacteria of citrus: Spiroplasma citri, agent of stubborn disease, Candidatus Liberibacter spp., associated with huanglongbing, Candidatus Phytoplasma aurantifolia, associated with witches' broom disease of lime, as well as of xylem-restricted bacteria: Xylella fastidiosa, agent of citrus variegated chlorosis (1969-1999). (iv) Etiology and management of citrus diseases in Brazil: Variegated chlorosis (1989-1993), Sudden Death (19982005), Huanglongbing 2005-2014).

J.M. Bové is member of the French Academy of Agriculture (1992), corresponding member of the French Academy of Science (1993), member of the Brazilian Academy of Science (2002), Fellow of the American Phytopathological Society (1994), Fellow of the International Organization of Citrus Virologists (2004). 
Citrus huanglongbing (HLB, or yellow shoot disease), affects by now the three major citrus- producing areas in the world: China since at least the 1930s [from the north-central region of China], Brazil since 2004, and Florida (USA) since 2005. In addition to Asia and America, Africa has carried the affliction since 1928 (Bové 2006). HLB has not yet been reported from Australia and the Mediterranean Basin, where, however, the disease is becoming increasingly the subject of great concern.

In addition to yellow shoots shown by young flushes on infected trees, the most characteristic HLB symptoms are leaves with blotchy mottle and yellow veins as well as fruits with color inversion (Bové 2006). On healthy maturing fruits, the yellow/orange color develops first at the stylar end, the pedoncular end being still green. Conversely, on HLB-affected fruits, it is the pedoncular end which colors first, the stylar end being still green. In addition, HLB-affected fruit is often lopsided and contains abnormal, brownish seeds.

Prof. Kung Hsiang Lin (1910-1986) in Guangzhou, China, was the first to show and publish (in 1956) that the disease, called huanglongbing by the farmers, was transmissible by graft inoculation and was therefore of infectious, probably viral, nature (Lin 1956a,b). Greening, the HLB-like disease in South Africa, was shown to be graft-transmissible in 1965 (McClean \& Oberholzer 1965), nine years after HLB in China. Therefore "huanglongbing" has precedence over "greening" and became the official name of the disease in 1995 (Moreno et al. 1996). Being graft-transmissible, HLB has also insect vectors: the African citrus psyllid, Trioza erytreae, reported as the vector in South Africa in 1965 and the Asian citrus psyllid, Diaphorina citri, identified as the vector in Asia (India and Philippines) in 1967 (Bové 2006).

In 1956, K. H. Lin thought HLB to be due to a virus disease because, in those days, the only infectious, grafttransmissible agents to be known were viruses. However, in Japan in 1967, wall-less bacteria (mycoplasmas) were added to the list of grafttransmissible agents of plants (Doi et al. 1967). Shortly thereafter, in 1970 in France, electron microscopy showed a phloem-restricted bacterium, but not a virus, to be associated with HLB and this bacterium was found in 1971 to possess a cell wall and was therefore not a mycoplasma (Bové 2006). The walled bacterium was detected in HLB-affected trees from both Asia and Africa. However in 1972, the HLB bacterium from Asia was found to be heat tolerant, whereas in Africa it was heat sensitive and occurred mainly in cool areas at altitudes above $\sim 600 \mathrm{~m}$ (Bové 2006; Bové et al. 1974). In the years to follow, the HLB bacterium, as seen in situ in the phloem sieve tubes, was shown by high resolution cytology to have a Gram-negative cell wall (Garnier et al. 1984). In spite of many attempts, permanent, axenic cultures of the HLB bacterium have not been obtained, even though in some cases the organism could be passaged three times before it would stop growing. Characterization of the HLB bacterium would eventually be achieved in the early 1990s when molecular, DNA-based techniques became available (PCR amplification and nucleotide-sequencing of 16SrDNA, 16S/23S intergenic region and beta-operon genes). In this way, the HLB bacterium was confirmed to be a Gram-negative organism and belonged to a new genus in the alpha subdivision of the Proteobacteria: the genus "Candidatus Liberibacter". In addition, the heatsensitive bacterium in Africa and the heat-tolerant bacterium in Asia represented two different species, which were named, respectively, Candidatus Liberibacter africanus (Laf) and Candidatus Liberibacter asiaticus (Las) (Jagoueix et al. 1994).

Thus, by 2003, it was well established that, in Africa, HLB was exclusively associated with Laf and transmitted by $T$. erytreae, and that, in Asia, the liberibacter was solely Las and the vector, Diaphorina citri (Bové 2006, 2013). Both Laf and T. erytreae being heat-sensitive, HLB in Africa turned out to be heat-sensitive; in Asia, heat-tolerance of HLB resulted from the heat-tolerance of Las as well as D. citri. Laf in Africa and Las in Asia are widely separated geographically, yet phylogenetically they are closely related. Continental drift can explain the geographical distance between Laf and Las, and the heattolerance of Las. Indeed, Nelson et al. (2013) have proposed that, on the ancient Gondwanan continent, the common ancestor of Laf and Las colonized the east coast of Africa as well as the continental plate carrying "India", which was originally attached to East Africa. Speciation of Laf occurred on the African east coast, while speciation of Las took place on the "India" plate drifting towards Asia and having to cross the Equator before reaching its present day position. Las is seen as having gained heat tolerance while submitted to the hot equatorial environment. No other liberibacter is heat-tolerant and no other liberibacter crossed the equator. All liberibacters, including those from Rutaceae (Laf, Las, Lam) as well as those from non-Rutaceae ( $C a$. L. solanacearum, Lso, Ca. L. 
europaeus, Leu) would be of Pangaean origin, Pangea being the ancient continent composed of Laurasia, north of the Equator, and Gondwana, south of it. Laf and Las would be of Gondwanan origin, while Lso, Leu and Lam - of Laurasian origin (Nelson et al. 2013).

In 2004, HLB symptoms were reported for the first time in the Americas and, more precisely, in São Paulo State, Brazil (Bové 2006; Teixeira et al. 2005a, b). Two liberibacters were found to be associated with the disease: a new, heat-sensitive liberibacter species, Candidatus Liberibacter americanus (Lam), and the known heattolerant Asian species, Las, both vectored by $D$. citri, the Asian citrus psyllid, that was reported in Brazil as early as 1942. In 2004-2005, most newly affected trees were infected with Lam, but now in 2014 Las dominates and Lam is rarely detected (Lopes et al. 2009).

From 2005 on, the rest of America and the Caribbean islands started to be invaded by Las and D. citri: first Florida, then Cuba (2006), followed by Mexico, Belize, Central America (2009-2010), Argentina, California, Guadeloupe, Texas (2012). In 2013, Lam was reported from Texas, in agreement with its proposed Laurasian origin (Nelson et al. 2013). In 2010, Las was reported for the first time from Africa and, more precisely, north Ethiopia (Saponari et al. 2010).

Worldwide, the vast majority of HLB-affected trees are infected with liberibacters. However, a few trees with leaf and fruit symptoms characteristic of HLB have been found to be free of liberibacters but infected with phytoplasma species. Such trees were first identified in São Paulo State in 2008 and were infected with a phytoplasma of group 16Sr IX (Teixeira et al. 2008); the same phytoplasma was also reported from Bahia state, Brazil, in 2012. In 2009, a phytoplasma of group $16 \mathrm{Sr} \mathrm{I}$, associated with HLB symptoms, was reported from China (Chen et al. 2009). These two HLB-associated phytoplasmas were reported from Mexico in 2013.

As soon as HLB was identified in São Paulo State in March 2004, the decision was taken by Fundecitrus and the major farms of the citrus industry to try to manage the disease by the three-pronged system (TPS), involving three measures: (i) reduction of the sources of inoculum by visual inspections of all trees on the farm for the detection of symptomatic trees and their eradication as quickly as possible; PCR was used to confirm that the observed symptoms were indeed those of HLB; (ii) replacement of the eradicated trees by healthy trees produced in nurseries having to be, by law, covered and insect-proof; (iii) control of D. citri, the psyllid vector of HLB in Brazil, by insecticide treatments of all trees. As such, the TPS is a preventive management system: it prevents as many trees as possible from becoming infected. In 2010, Fundecitrus and 18 major citrus farms shared their results on HLB management by the TPS and, for the first time, lessons on how to manage HLB were learned and factors that make it easier or more difficult to achieve HLB-control were identified (Belasque et al. 2010).

Management is successful when it keeps the percentage of HLB-affected trees on the farm below $1 \%$. Without management the percentage of HLB-affected trees increases rapidly. In one experiment the percentage rose, within 3 years, from $2 \%$ to $23 \%$. Thus, management should start as quickly as possible after detection of the first HLB-affected trees on the farm, knowing also that, besides infected trees with HLB symptoms, there are also infected trees that show no symptoms yet. Up to $15 \%$ symptomatic trees, the percentage of infected symptomless trees is roughly as high as the percentage of symptomatic trees: $\%$ infected trees (symptomatic + symptomless) $=2 \mathrm{x} \%$ symptomatic trees. Inspections for symptomatic trees have been made easier by the use of tractor-pulled platforms carrying two or four inspectors, respectively, for young or mature trees. Even so, visual inspections do not detect all the symptomatic trees present on the farm at a given time; the result is only $60 \%$ to $70 \%$. For all these reasons, several inspections have to be carried out each year: four is a minimum, 12 may be necessary when aggressive management is required due to "bad" neighboring farms (see below). Needless to say, visual inspections by inspectors identify only symptomatic trees. Techniques for identification of all infected trees, with and without symptoms, would be of great help.

Control of the HLB psyllid vector by insecticide treatments was greatly improved when it was discovered that more trees become infected at the borders of the farm than inside the farm (border effect). This means that borders should be treated more frequently than the rest of the farm. Also, the tree density should be higher at the borders to compensate for the larger number of symptomatic trees to be eradicated. The border effect is increased by the presence of "bad" neighboring farms, i.e., farms with no or only poor HLB management. Such "bad" farms, close to "good" farms, have been a major problem for efficient HLB management. Young trees, because of their many 
flushes, especially when under irrigation, need more aggressive management than mature trees. They should be treated with systemic insecticides, at least until their third year in the field. In South Africa, trunk application of insecticides, especially to young trees, has often been preferred over foliar applications. In São Paulo State, a minimum of six foliar insecticide applications per year is required; two applications per month are at the upper limit; borders may be treated weekly; four to five annual airplane applications are practiced on large farms or at the regional level. In Florida, growers often control adult psyllids by making two "dormant" sprays, one immediately after the fall lush period and one prior to early spring flush. Finally, insecticide rotations are of common practice to prevent resistance build-up.

For HLB management, growers can only act on (i) inspections for eradication of symptomatic trees, (ii) replacement of eradicated trees by healthy nursery trees and (iii) insecticide treatments for psyllid control. They are free to choose the number of inspections, with or without platforms, the number of insecticide treatments, the type of insecticide used and the insecticide application method. Growers also decide when to start management, whether to replace eradicated trees or not. However, other factors are also important for HLB management on which the growers cannot act: size of the farm, shape of the farm, age of the trees, incidence of HLB in the area where the farm is located, presence of "bad" neighboring farms. Essentially, because of the border effect, large farms ( $>400$ hectares) with a square shape can be managed successfully, whereas small farms with a flat, elongated rectangular shape will have proportionally more border surface and will be more difficult - if at all possible - to manage.

In São Paulo State, HLB management by the TPS has been highly successful because of the many large farms, but also because it has been practiced properly, including not only psyllid control but also removal of symptomatic trees. In Florida, growers have been reluctant to remove affected trees, most farms are relatively small, and the citrus industry is in great danger, with more than $50 \%$, if not $75 \%$, of HLB-infected trees. In São Paulo State, HLB management by the TPS has resulted in 200,000 ha of citrus with less than $1 \%$ affected trees (Bové 2012). In the long term, this State has two options: (i) an option based on the development of genetically modified citrus cultivars resistant to HLB or repelling/killing the psyllid vector; probably, 5 to 15 years - at the best - will be required to have these trees in the orchards; (ii) an option based on the 200,000 ha of managed citrus with less than 1\% HLB-affected trees, provided HLB-management by the TPS is maintained. In Florida, nutritional sprays have been used to maintain citrus trees in production in spite of HLB. This procedure seems to be unsuccessful in São Paulo State.

HLB management by the TPS is by no means an easy procedure and, as indicated above, requires certain conditions, such as large farms, to be successful. Some of these conditions do not seem to be present in Israel, where small farms are the majority. A solution to overcome this problem might come from the development of Citrus Health Management Areas (CHMA), where HLB management could be applied simultaneously to all citrus farms in the Area, each farm being considered more or less as a block of a large farm; no "bad" farms should be allowed to exist in the CHMAs.

The countries around the Mediterranean Sea are still free of HLB and/or HLB psyllid vectors, except Portugal and Spain; Madeira and Canary Islands carry the African psyllid, Trioza erytreae, since 1994 and 2002, respectively, but the disease itself has not been reported. Morocco is among the endangered countries. To the east of the Mediterranean Basin, Iran has been affected since 2008; the disease and its Asian vector, D. citri, might get close to Turkey. North of the Red Sea, in the southern part of the Arabian Peninsula, Saudi Arabia and Yemen carry Asian and African HLB as well as the Asian and African HLB psyllid vectors as a result of incursions in modern times (Bové 2013). In Africa, south of the Red Sea, Eritrea and north Ethiopia carry African HLB and vector; Asian HLB was reported from north Ethiopia in 2010 (Saponari et al. 2010). Awareness campaigns aimed at HLB and the two psyllid vectors, as well as measures to reinforce quarantine, should help in eradicating HLB and the vectors if they enter Israel, if keeping them out of the country fails. Citrus will not be destroyed worldwide, but in certain regions it will happen.

\section{References}

Belasque, J., Jr., Bassanezi, R. B., Yamamoto, P. T., Ayres, A. J., Tachibana, A., Violante, A. R., et al. (2010). Lessons from huanglongbing management in São Paulo State, Brazil. Journal of Plant Pathology, 92, 285-302. 
Bové, J. M. (2006). Huanglongbing: a destructive, newlyemerging, century-old disease of citrus. Journal of Plant Pathology, 88, 7-37.

Bové, J. M. (2012). Huanglongbing and the future of citrus in São Paulo State, Brazil. Journal of Plant Pathology, 94, 465-467.

Bové, J. M. (2013). Heat-tolerant Asian HLB meets heat-sensitive African HLB on the Arabian Peninsula. Why? 3rd International Research Conference on HLB (Orlando, FL, USA).

Bové, J. M., Calavan, E. C., Capoor, S. P., Cortez, R. E., \& Schwarz, R. E. (1974). Influence of temperature on symptoms of California stubborn, South African greening, Indian citrus decline and Philippines leaf mottling diseases. Proceedings of the $6^{\text {th }}$ Conference IOCV (pp. 12-15, Univ. of California, Riverside, CA, USA).

Chen, J., Pu, X., Deng, X., Liu, S., Li, H., \& Civerolo, E. (2009). A phytoplasma related to "Candidatus Phytoplasma asteris" detected in citrus showing huanglongbing symptoms in Guangdong, P. R. China. Phytopathology, 99, 236-242.

Doi, Y., Teranaka, M., Yora, K., \& Asuyama, H. (1967). Mycoplasma or PTL group-like microorganisms found in the phloem elements of plants infected with mulberry dwarf, potato witches' broom, aster yellows, or paulownia witches' broom. Annals of the Phytopathological Society of Japan, 33, 259-266.

Garnier, M., Danel, N., \& Bové, J. M. (1984). Aetiology of citrus greening disease. Annals of Microbiology (Institut Pasteur), 135A, 169-179.

Jagoueix, S., Bové, J. M., \& Garnier, M. (1994). The phloemlimited bacterium of greening disease of citrus is a member of the $\alpha$ subdivision of the Proteobacteria. International Journal of Systematic Bacteriology, 44, 370-386.

Lin, K. H. (1956a). Yellow shoot of citrus [in Chinese]. Acta Phytopathologica Sinica, 2, 1-12.

Lin, K. H. (1956b). Etiological studies of yellow shoot of citrus [in Chinese]. Acta Phytopathologica Sinica, 2, 12-42.
Lopes, S., Bertolini, E., Frare, G., Martins, E. C., Wulff, N. A., Teixeira, D. C., et al. (2009). Graft transmission efficiencies and multiplication of "Candidatus Liberibacter americanus" and "Ca. Liberibacter asiaticus" in citrus plants. Phytopathology, 99, 301-306.

McClean, A. P. D., \& Oberholzer, P. C. J. (1965). Greening disease of sweet orange: evidence that it is caused by a transmissible virus. South African Journal of Agricultural Science, 8, 253-276.

Moreno, P., da Graça, J. V., \& Yokomi, R. K. (1996). Preface. In: Proceedings of the $13^{\text {th }}$ Conference IOCV (p. iv, Univ. of California, Riverside, CA, USA.) <www.ivia.es/iocv/>

Nelson, W. R., Munyaneza, J. E., McCue, K. F., \& Bové, J. M. (2013). The Pangaean origin of 'Candidatus Liberibacter' species. Journal of Plant Pathology, 95, 455-461.

Saponari, M., De Bac, G., Breithaupt, J., Loconsole, G., Yokomi, R. K., \& Catalano, L. (2010). First report of 'Candidatus Liberibacter asiaticus' associated with huanglongbing in sweet orange in Ethiopia. Plant Disease, 94, 482.

Teixeira, D. C., Ayres, A. J., Kitajima, E. W., Tanaka, F. A. O., Danet, J. L., Jagoueix-Eveillard, S., et al. (2005a). First Report of a Huanglongbing-like Disease of Citrus in Sao Paulo State, Brazil, and association of a new Liberibacter species, "Candidatus Liberibacter americanus", with the disease. Plant Disease, 89, 107.

Teixeira, D. C., Saillard, C., Eveillard, S., Danet, J. L., Ayres, A. J., \& Bové, J. M. (2005b). 'Candidatus Liberibacter americanus' sp. nov., associated with citrus huanglongbing (greening disease) in São Paulo State, Brazil. International Journal of Systematic and Evolutionary Microbiology, 55, 1857-1862.

Teixeira, D. C., Wulff, N. A., Martins, E. C., Kitajima, E. W., Bassanezi, R., Ayres, A. J., et al. (2008). A phytoplasma closely related to the Pigeon pea witches' broom phytoplasma (16Sr IX) is associated with citrus huanglongbing symptoms in the State of São Paulo, Brazil. Phytopathology, 98, 977-984. 